\title{
Challenges Of Virtual Mode Of Education Faced By The Higher Secondary Students During Covid 19 Lockdown
}

\author{
Dr. Rumpa Das \\ Faculty, Department of Education, Cotton University. Email- das.rumpadas.rumpa02@gmail.com
}

\begin{abstract}
The virtual mode of education became popular during the lockdown which was the result of the Covid-19 pandemic. Education of the country cannot be stopped as it can affect the countries in an adverse way. Education plays an important role in the development of any country. In the pandemic virtual mode of education acts as a saviour for the students and provides a way for the students to continue their studies by following the social distancing. However, having several benefits it has major challenges which are faced by the students of higher education. Research methodology can maintain overall strategy and procedure of this study. Positivism research philosophy has been selected for this study. Deductive research approach has been selected in this study. Secondary data collected from published journal, books, and articles for this study. Along with his secondary data analysis process is used in this study. Descriptive research design has been selected for this study. Main objective of this study is to identify challenges of virtual mode of education. This study is trying to justify impact of this virtual mode of education on Higher Secondary students during Covid-19 outbreak.
\end{abstract}

Keywords:

Pandemic, Covid-19, Challenges, Development, Education and Lockdown.

Article Received: 18 October 2020, Revised: 3 November 2020, Accepted: 24 December 2020

\section{Introduction}

COVID-19 pandemic has affected us in many ways. The study of the students has been disturbed by the pandemic. The lockdown in the pandemic results in the closure of the offline schools and initiated the virtual mode of education for not interrupting the education of the students. A virtual model of education has several benefits and it is adapted by the educational researchers as it saves time and money as well as it focuses on the updated syllabus. In the lockdown, it acts as a boon for the students as well as the education system. At the same time, there are so many challenges faced by the students of Higher Secondary education as they have to suddenly change their mode of education which creates pressure on them to complete their syllabus. The problems of the virtual model of education cannot be fixed however it can be reduced by taking some major actions by the government.

\section{Overview of Virtual Mode of Education}

A virtual model of education came with the perspective to continue the education of the Higher Secondary students during the pandemic of COVID-19. According to Liu et al. (2017), education is the primary concern of any country as an interruption in education has long term serious adverse effects on the economies as well as on the societies. Unfortunately, the Virtual mode of education is limited to a certain section of society and not much beneficial as it was predicted. Several challenges arise in the virtual model of education. The students special the Higher Secondary students have faced various challenges due to the virtual mode of challenges. They face problems due to the unequal distribution of net and the poor connection of the net and the students who belong to the poor section can't afford smartphones. According to Fung et al. (2019), virtual mode of education acts as a boon for the students at the same time it creates trouble for the Higher Secondary education that have their exams and they have to finish their syllabus on time. The students have to develop an 
understanding with the virtual model of education as they are addicted to the offline mode of education. In the pandemic, it was mandatory to follow the social distancing which was impossible in the offline mode of education. A virtual model of education was initiated to avoid interruption in education.

\section{Importance of Virtual Mode of Education}

A virtual model of education provides several advantages to the students during the pandemic period of COVID-19. As in the pandemic time, it was mandatory to follow the social distancing which is almost impossible to maintain social distancing in offline mode of education. According to Arora and Srinivasan (2020), there are several advantages of Virtual mode of education. The students can complete their syllabus in less time as compared to offline mode of education. The students avoided travelling during the pandemic period as they don't have to go anywhere for attending the online classes. Their class was at their home. By using the Smartphone in their study room they can reach school. In the virtual model of education, the time was also flexible as there was no strict time to attend the class. They got abundant time to complete their task in the virtual model of education.

Not only in the COVID-19 period but also a virtual model of education is being preferred by most of the countries and the students as it can provide education just by two things the first one is having a Smartphone and the second one is Internet connectivity. According to Khurshid et al. (2020), it is liked by the students as it saves the time of travelling they don't have to go in a particular building for getting an education instead of that the school comes to their home. Just by using a Smartphone, they complete their study. The second reason for being liked by the students is that virtual modes of education have updated syllabus, not like the syllabus of offline education. The educationists are also liking the concept of virtual mode of education as they don't have to invest in making a building and creating an infrastructure for the students. The maintenance charge of the building of the schools is also high. In the offline mode of education at the regular interval, the students have to pay extra charges for the extra co-curricular activities which make the education more expensive. According to $\mathrm{Ng}$ et al. (2020), in the case of virtual education, they don't have to pay extra charges for unnecessary activities.

In the virtual model of education, the same lecture can be seen many times when the students want to revise the chapter. More than sufficient information is available in the virtual model of education which will provide benefit to the students. In the pandemic time no doubt, virtual mode of education has saved the education and the students. Unfortunately, there are several challenges which are faced by the students especially by the Senior Secondary students who have their final exams this year. Challenges of the students are discussed in the next topic.

\section{Challenges faced by the Higher Secondary}

\section{Students}

There is no doubt that the virtual model of education has several benefits and became popular in less time. According to Garbe et al. (2020), the pandemic COVID-19 acts as a boon for the virtual model of education and became more popular than being more popular. However, there are various challenges faced by the Higher Secondary students as the exam of the Higher Secondary students is the first steps towards their career. The pressure faced by the Higher Secondary students is at the peak level. In this period, the sudden change in the mode of education is itself a challenging task for the students. Many of the students who are in the Higher Secondary classes are addicted to the offline mode of education and they are not aware of online education. Sudden changes in the mode of education can adversely affect their performance in the exam. They have to complete their syllabus on the time as their exam can be declared as the first step towards their career. According to Sahi et al. (2020), the unequal distribution of the internet became the 
major challenges for the students. The students can practice online classes and become habitual of using online classes. However, some sections of the students are not economically sound and they don't have smartphones and the net connection is also very expensive.

The pandemic has already damaged the country's economy and the Higher Secondary students who belong to the poor background faced many difficulties in continuing their studies. According to Gamage et al. (2020), the other problem faced by those Higher Secondary students who belong to the areas where the availability of the net connectivity is very poor. The students faced various difficulties in the completion of their syllabus as they don't have a good network connection. The problem of the poor network is not only faced by the students of rural areas but also sometimes faced by the students of urban areas like buffering and lagging of the live stream. The syllabus designed for the students of higher education is a bit tougher than the previous class as it is a career deciding year for them. According to Palvia et al. (2018), the pattern of the syllabus is a bit different from what they read in previous classes. Therefore, the students need proper guidance for completing the syllabus. In the virtual model of classes, proper guidance and proper teaching are difficult. In the offline classes, the students are benefited by the proper guidance of the teacher.

Perhaps, the students lost motivation by the burden of the syllabus; in that case, the offline teachers can motivate them which is missed in the virtual model of education. In Higher Secondary education, practical knowledge of the syllabus is also needed which will help the student carry forward that knowledge for their upcoming career. In the virtual model of education, practical education was completely ignored as they only focused on theoretical knowledge. According to Toquero (2020), the students who were bordering the hostel suddenly leave the hostel and pg without carrying their notebooks and laptops to their home due to this sudden pandemic. The lockdown extended and the students were unable to bring their books and notebooks which made them anxious about their exams. The other problem faced by the students was the way of teaching offline and online. Most of the students were attending the online classes for the first time and they were not familiar with the teaching style of the virtual model of education.

They got troubled and faced difficulties in understanding the concepts that were taught. According to Kassab et al. (2020), they were habitual of asking the doubts in the offline class during the lecture unfortunately they didn't get a chance to clear the doubt whenever they want. For most of the students, study became the most hectic and disgusting task during the pandemic period. Understanding the concepts became much more difficult and time-consuming as compared to offline education. The physical appearance of the teacher in the offline classes' keeps them motivated as well as they got proper guidance by them which was eliminated in the virtual model of education. For checking the performance of the students, the various tests were conducted in the offline classes which support the students to improve their performance for their final exams. In the virtual model of education, tests were conducted however; the students may give their test by using unfair means as there are no invigilators present. The students need to be punctual and disciplined for studying which is not provided in the virtual model of education and they distract from their ambition.

Table1: Access and Knowledge of computer and Internet at household and person-level

\begin{tabular}{|l|c|c|c|c|}
\hline & $\begin{array}{c}\text { Household } \\
\text { Access }\end{array}$ & $\begin{array}{c}\text { Household } \\
\text { Access }\end{array}$ & Person Use & Person Use \\
\hline
\end{tabular}




\begin{tabular}{|c|c|c|c|c|}
\hline & Computer & Internet & $\begin{array}{c}\text { Operate } \\
\text { Computer }\end{array}$ & Use the Internet \\
\hline Rural & 4.79 & 15.98 & 8.67 & 11.96 \\
\hline Urban & 22.34 & 42.27 & 31.40 & 36.1 \\
\hline Male & 10.13 & 23.79 & 18.96 & 23.94 \\
\hline Female & 10.23 & 22.70 & 13.5 & 13.6 \\
\hline Total & 11.23 & 23.23 & 15.53 & 20.1 \\
\hline
\end{tabular}

\section{The solution to those challenges}

Education is the primary thing in any country. No matter if it is a virtual model of education or offline mode of education the prime aim is to continue the education and it should not be interrupted by any pandemic. According to Huda et al. (2019), in the COVID-19 pandemic, the virtual model of education has initiated intending to complete the syllabus of the students, however; the majority of the students are not benefited by it as it was predicated. We have seen that the students of higher education are facing various difficulties to develop an understanding with the virtual model of education as they are addicted to offline mode of education. The challenges like smartphones and net connectivity are the major challenges which are faced by the students. To overcome these problems the government must take an initiative to distribute the Smartphone to every student who has their final exams.

The government should also provide better net connectivity in all the areas whether it is urban or ruler so that the study of the students cannot be interrupted and the government should also think on the price of the network connectivity. According to Cloete (2017), the price of the net especially for the students should be cheap so that all the students can get benefitted by the virtual model of education. In the pandemic time, the students who are not habitual of the virtual model of education are facing lots of trouble while completing the syllabus. The government should think about the syllabus of the students and they should be given some relaxation in their syllabus which will put less pressure on them.

\section{Conclusion}

In this article, we have studied the various challenges which are faced by the students of Higher Secondary education. We came to know that Higher Secondary education exams are the first steps towards the career of the students. Sudden change in the mode of education has created various difficulties for the students. From understanding the topics to completing the syllabus students faced various troubles. In the virtual model of education demotivation also occurs among the students as the syllabus gets a little bit more difficult than the syllabus they have earlier read. In this career deciding year, the changes in their education mode became difficult for them. No doubt there are several benefits of the virtual mode of education as it acts as a saviour of the education in the time of the pandemic. The students have completed their syllabus by the virtual model of education. It can be happily accepted by the students by reducing its challenges like availability of smartphones to every student and by reducing the price of network connectivity for the student's virtual mode of education.

\section{Reference}

[1] Arora, A.K. and Srinivasan, R., 2020. Impact of pandemic COVID-19 on the teaching-learning process: A study of 
higher education teachers. Prabandhan: Indian journal of management, 13(4), pp.43-56.

[2] Arora, A.K. and Srinivasan, R., 2020. Impact of pandemic COVID-19 on the teaching-learning process: A study of higher education teachers. Prabandhan: Indian journal of management, 13(4), pp.43-56.

[3] Cloete, A.L., 2017. Technology and education: Challenges and opportunities. HTS Theological Studies, 73(4), pp.1-7.

[4] Fung, F.M., Choo, W.Y., Ardisara, A., Zimmermann, C.D., Watts, S., Koscielniak, T., Blanc, E., Coumoul, X. and Dumke, R., 2019. Applying a virtual reality platform in environmental chemistry education to conduct a field trip to an overseas site.

[5] Gamage, K.A., Wijesuriya, D.I., Ekanayake, S.Y., Rennie, A.E., Lambert, C.G. and Gunawardhana, N., 2020. Online delivery of teaching and laboratory practices: Continuity of university programmes during COVID-19 pandemic. Education Sciences, 10(10), p.291.

[6] Garbe, A., Ogurlu, U., Logan, N. and Cook, P., 2020. Parents' experiences with remote education during COVID-19 school closures. American Journal of Qualitative Research, 4(3), pp.45-65.

[7] Huda, M., Ahsan, A., Basuki, S., Rismayadi, B., Jasmi, K.A., Basiron, B. and Mustari, M.I., 2019. Empowering Technology Use to Promote Virtual Violence Prevention in Higher Education Context. Intimacy and Developing Personal Relationships in the Virtual World, pp.272-291.

[8] Kassab, M., DeFranco, J. and Laplante, P., 2020. A systematic literature review on the Internet of things in education: Benefits and challenges. Journal of Computer Assisted Learning, 36(2), pp.115-127.
[9] Khurshid, Z., De Brún, A., Moore, G. and McAuliffe, E., 2020. Virtual adaptation of traditional healthcare quality improvement training in response to COVID-19: a rapid narrative review. Human resources for health, 18(1), pp.1-18.

[10] Liu, D., Bhagat, K.K., Gao, Y., Chang, T.W. and Huang, R., 2017. The potentials and trends of virtual reality in education. In Virtual, augmented, and mixed realities in education (pp. 105-130). Springer, Singapore.

[11] Ng, Y.M. and Peggy, P.L., 2020. Coronavirus disease (COVID-19) prevention: Virtual classroom education for hand hygiene.

[12] Palvia, S., Aeron, P., Gupta, P., Mahapatra, D., Parida, R., Rosner, R. and Sindhi, S., 2018. Online education: Worldwide status, challenges, trends, and implications.

[13] Sahi, P.K., Mishra, D. and Singh, T., 2020. Medical education amid the COVID-19 pandemic. Indian pediatrics, 57(7), pp.652-657.

[14] Toquero, C.M., 2020. Challenges and Opportunities for Higher Education Amid the COVID-19 Pandemic: The Philippine Context. Pedagogical Research, 5(4). 